\title{
PENGGUNAAN TEMPLATE STUDY PLANNER UNTUK MENUNJANG PROSES SELF-DIRECTED LEARNING - SEBUAH STUDI LITERATUR
}

\author{
Halimah Thania Nasution*, Gandes Retno Rahayu**, Tridjoko Hadianto*** \\ * Mahasiswa Program S2 IImu Pendidikan Kedokteran FK UGM \\ ** Departemen Pendidikan Kedokteran, Fakultas Kedokteran Universitas Gadjah Mada \\ *** Departemen Parasitologi, Fakultas Keodkteran Universitas Gadjah Mada
}

\begin{abstract}
Background: Self-directed learning is a form of independent learning where in the process it is advisable that students create a study planner so that the learning process is more focus and effective. A study planner can be used as a reference that will assist students in evaluating and reflecting the learning process. This study aimed to find out how the application of study planner can support the process of self-directed learning, this will be based on a literature study.

Method: This research was in the form of a literature study which covered the application of study planner and its relation to self-directed learning. The literature searches were conducted with two databases (e-sources national library and ERIC), by using 11 keywords, in order to obtain more amounts of readings available, that were in relation to the utilization of study planner in order to support self-directed learning. Based on five inclusion and exclusion criteria were used to select 22 journals that obtained from the results of database searches, two journals that can be used to answer research questions were found. Data were extracted systematically by segmenting and coding. Followed by determining patterns to find broader category.

Results: Based on segmenting and coding process and determining important patterns, two broad categories were found, that are (1) The benefit of study planner in self-directed learning; and (2) Factors that affect study planner and self-directed learning.

Conclusion: Study planner can assist students in developing their self-directed learning skills, that will be handy to support their lifelong learning skills. Study planner can also give motivations to students in performing self-directed learning
\end{abstract}

Keywords: self-directed learning, study planner

\section{ABSTRAK}

Latar belakang: Self-directed learning merupakan salah satu bentuk belajar mandiri, dimana, pada prosesnya mahasiswa sebaiknya membuat sebuah study planner terlebih dahulu, agar proses belajar yang akan dikerjakan lebih terarah dan tepat sasaran. Study planner ini dapat digunakan sebagai acuan yang dapat membantu mahasiswa dalam melakukan evaluasi dan refleksi belajar mandiri. Penelitian ini bertujuan untuk mengetahui bagaimana penggunaan study planner dalam menunjang proses self-directed learning.

Metode: penelitian ini berupa studi literatur yang mengulas tentang penggunaan study planner dan hubungannya dengan self-directed learning. Pencarian literatur dilakukan pada 2 database (e-resources perpustakaan nasional dan ERIC) dengan menggunakan 11 kata kunci, yang bertujuan untuk memperoleh seluruh literatur yang ada, yang berkaitan dengan penggunaan study planner dalam menunjang proses self-directed learning. Berdasarkan 5 kriteria inklusi dan eksklusi yang digunakan untuk menyeleksi 22 jurnal yang diperoleh dari hasil pencarian di databased, ditemukan 2 jurnal yang bisa digunakan untuk menjawab pertanyaan penelitian.

korespondensi: hthania@gmail.com 
Data di ekstraksi dengan sistematis dengan melakukan segmenting dan coding. Dilanjutkan dengan penentuan pola - pola penting untuk mencari kategori besar.

Hasil: berdasarkan proses segmenting dan coding dan penentuan pola - pola penting, ditemukan 2 kategori besar yaitu (1) Manfaat penggunaan study planner terhadap self-directed learning, dan (2) Faktor - faktor yang mempengaruhi study planner dan self-directed learning.

Kesimpulan : study planner atau yang sejenisnya dapat membantu mahasiswa dalam melatih keterampilan selfdirected learning pada mahasiswa. Study planner ini juga dapat memberikan motivasi kepada mahasiswa dalam melakukan proses self-directed learning.

Kata kunci: self-directed learning, study planner

\section{PENDAHULUAN}

Mengaplikasikan self-directed learning tidak semudah yang tertulis dalam teori - teori. Salah satu bentuk permasalahan yang bisa timbul pada saatimplementasi self-directed learning adalah fluktuasi antara chaos (frustration, disorientation) dan cosmos (structures they themselves constructed). ${ }^{1}$ Permasalahan lain yang bisa muncul yaitu, perbedaan pendapat perihal konsep dan maksud dari student-centered learning, dan maksud dari self-directed learning, serta hubungan konsep ini dalam mencapai tujuan pembelajaran, yang bisa berarah kepada munculnya rasa frustasi pada mahasiswa. Selama masih ada perbedaan pendapat mengenai maksud dan pengertian dari self-directed learning dan student-centered learning dalam institusi, maka permasalahan - permasalahan ini tidak akan terpecahkan. $^{2}$

Proses belajar mandiri yang terancang dengan baik akan mendorong mahasiswa untuk lebih aktif dalam mengikuti proses belajar. Oleh karena itu, sebelum melakukan belajar mandiri, mahasiswa sebaiknya perlu membuat rencana belajar mandiri (study planner) agar proses belajar lebih terarah, dan tepat sasaran. Dengan menentukan sendiri arah belajar yang diinginkan mahasiswa, dapat menumbuhkan rasa tanggung jawab dan rasa kepemilikan terhadap proses belajar tersebut. ${ }^{3,4}$

Dalam membuat sebuah study planner, mahasiswa bisa menentukan sendiri topik yang dipelajari, kedalaman dan luas topik belajar, sumber belajar, waktu belajar dan tempat mereka akan melakukan belajar mandiri. Rencana belajar mereka ini bisa dituliskan ke dalam study planner, sebagai pengingat keseluruhan rencana belajar yang akan dikerjakan. ${ }^{4}$ Selain itu, mereka juga bisa membuat pertanyaan-pertanyaan lain, yang ingin dicari, yang berkaitan dengan topik yang akan mereka pelajari. ${ }^{3.5}$

Mereka juga bisa menuliskan refleksi diri berupa hal-hal yang telah mereka pelajari, hal yang ingin diketahui dari sebuah topik, kelemahan belajar yang perlu mereka tingkatkan, serta harapan mereka di masa datang. ${ }^{4}$ Refleksi diri ini bisa menjadi bahan diskusi dengan sesama mahasiswa, untuk menemukan sebuah solusi belajar apabila ada permasalahan yang belum terpecahkan.

Refleksi diri ini juga merupakan bahan bukti, terlaksananya proses belajar yang telah disusun mahasiswa dalam study planner. Daftar topik ini bisa dijadikan pegangan bagi mahasiswa untuk membuat sebuah evaluasi belajar, untuk mengetahui tingkat penguasaan topik yang telah mereka pelajari. ${ }^{4}$

Proses belajar mandiri tidak harus dilakukan dalam kesendirian, mahasiswa bisa berdiskusi dengan teman sesama mahasiswa mengenai permasalahan belajar mereka. Teman sesama mahasiswa akan menjadi seorang partner dalam belajar, meskipun tugas partner tersebut hanya sebatas membantu mengarahkan rencana belajar mandiri mahasiswa. ${ }^{4}$

Dalam penelitian ini, peneliti melakukan sebuah studi literatur mengenai penggunaan studi planner untuk menunjang proses self-directed learning. Penelitian ini bertujuan untuk melihat penggunaan study planner untuk menunjang proses self-directed learning. 


\section{METODE}

Penelitian ini merupakan sebuah studi literatur yang menulis tentang penggunaan study planner untuk menunjang self-directed learning. Pada penelitian ini, peneliti dibantu oleh dua orang asisten peneliti, yang bertugas untuk membantu pencarian literatur pada dua databased (1 orang) dan membantu proses ekstraksi data (1 orang).

Pencarian literatur dengan mengakses internet pada dua database yaitu : (1) E-resources perpustakaan nasional, dan (2) ERIC (Education Resources Information Center). Pencarian literatur dimulai sejak tanggal 5 Januari s/d 16 Januari 2016. Pencarian literatur menggunakan kata - kata kunci sebagai berikut :

1. "study planner $\mathcal{E}$ self-directed learning"

2. "study plan + self-directed learning+medical"

3. "study plan"

4. "study planner in self-directed learning"

5. "study plan $\mathcal{E}$ self-directed learning"

6. "study plan + medical education"

7. "study plan $\mathcal{E}$ self-regulated learning"

8. "personal learning plan and self-directed learning"

9. "study planning $\mathcal{E}$ independent learning"

10. "personal learning plan $\mathcal{E}$ self-regulated learning"

11. "personal learning plan $\mathcal{E}$ independent learning"
Literatur yang digunakan adalah literatur yang dipulikasikan dalam 10 tahun terakhir dan hanya literatur yang bisa diakses secara gratis.

Berdasarkan kata - kata kunci diperoleh 22 literatur, yang berkaitan dengan study planner atau sejenisnya, dan self-directed learning. Seluruh literatur kemudian diseleksi kembali dengan menggunakan kriteria inklusi dan eksklusi, yaitu:

1. Penelitian dalam literatur berupa studi kualitatif ataupun kuantitatif.

2. Penelitian dalam literatur menggunakan alat bantu berupa study planner atau sejenisnya, serta melihat hubungan penggunaan study planner atau sejenisnya dengan self-directed learning.

3. Sampel penelitian yang digunakan dalam literatur adalah mahasiswa, dan penelitian yang ada dalam literatur dilaksanakan di Institusi pendidikan tinggi (universitas dan sejenisnya)

4. Literatur dapat diakses dengan tanpa berbayar.

5. Literatur bukan sebuah ulasan teori, opini, atau yang sejenisnya.

Berdasarkan kriteria inklusi dan ekslusi diatas, diperoleh 2 jurnal yang mampu menjawab pertanyaan penelitian, dengan rincian seleksi sebagai berikut:

Tabel 1. Seleksi literatur yang akan digunakan.

\begin{tabular}{cccl}
$\begin{array}{c}\text { Jumlah } \\
\text { Literatur }\end{array}$ & $\begin{array}{c}\text { Memuat } \\
\text { kriteria }\end{array}$ & $\begin{array}{c}\text { Tidak memuat } \\
\text { kriteria }\end{array}$ & \multicolumn{1}{c}{ Keterangan } \\
\hline 14 literatur & $1,3,4,5$ & 2 & - \\
1 literatur & $1,4,5$ & 2,3 & - \\
1 literatur & $1,2,4$ & 5,3 & - \\
2 literatur & $1,4,5$ & 3,2 & $\begin{array}{l}\text { Pada kriteria 2: penelitian menggunakan study plan atau yang } \\
\text { sejenisnya, tetapi tidak melihat hubungannya dengan self- } \\
\text { directed learning }\end{array}$ \\
1 literatur & 4 & $1,2,3,5$ & $\begin{array}{l}\text { Pada kriteria 2: penelitian hanya menceritakan tentang self- } \\
\text { directed learning, tanpa menggunakan study plan }\end{array}$ \\
1 literatur & $1,3,4,5$ & 2 & $\begin{array}{l}\text { Pada kriteria 2: penggunaan study plan atau sejenisnya, hanya } \\
\text { merupakan 1 bagian dari alat penelitian yang digunakan, yaitu } \\
\text { berupa website page untuk online course. } \\
\text { Penelitian ini tidak membahas lebih lanjut tentang pengguna- } \\
\text { an study planner atau sejenisnya, dan bagaimana penggunaannya } \\
\text { terhadap self-directed learning. }\end{array}$ \\
\hline literatur & $1,2,3,4,5$ & - & \\
\hline
\end{tabular}


Pengambilan/ekstraksi data dilakukan oleh peneliti yang dibantu oleh satu orang asisten penelitian. Literatur yang diperoleh kemudian dibaca berulang kali oleh peneliti yang dibantu oleh satu asisten peneliti. Setelah membaca literatur, ditemukan segmen - segmen unit analisis bermakna yang penting pada literatur. Dan setelah membaca ulang kembali literatur dan segmen - segmen unit analisis ini, tiap segmen unit analisis kemudian diberikan kode (coding) pengelompokan data. ${ }^{6}$

Setelah peneliti dan asisten peneliti masing - masing melakukan proses segmenting dan coding, peneliti dan asisten peneliti mendiskusikan temuan data dan isi literatur dan menemukan pola-pola penting.
Pola-pola ini kemudian dikategorisasikan menjadi 2 kategori besar.

\section{HASIL DAN PEMBAHASAN}

Data yang ditemukan pada studi literatur ini dikategorikan menjadi 2 kategori besar, yakni manfaat penggunaan elemen study planner terhadap self-directed learning (SDL), dan faktor-faktor yang mempengaruhi study planner dan self-directed learning (SDL).

Manfaat penggunaan elemen study planner terhadap self-directed learning dapat dikategorikan menjadi beberapa elemen seperti yang dapat dilihat pada tabel 2.

Tabel 2. Manfaat penggunaan study planner atau sejenisnya terhadap SDL

\begin{tabular}{|c|c|c|}
\hline No. & Manfaat & $\mathrm{Du}, 2012^{7}$ \\
\hline 1. & $\begin{array}{l}\text { Melakukan refleksi } \\
\text { diri }\end{array}$ & $\begin{array}{l}\text { "Penggunaan jurnal refleksi mampu } \\
\text { mendokumentasikan pengalaman - pengalaman, } \\
\text { ide - ide, pemikiran - pemikiran, dan kesimpulan } \\
\text { dari study plan yang dirancang mahasiswa." }\end{array}$ \\
\hline
\end{tabular}

2. Monitoring aktifitas "Dokumentasi/catatan belajar dari mahasiswa SDL dapat digunakan dosen sebagai patokan evaluasi dari efektifitas self-directed learning."

\begin{tabular}{|c|c|c|c|}
\hline 1. & $\begin{array}{l}\text { Melakukan refleksi } \\
\text { diri }\end{array}$ & $\begin{array}{l}\text { "Penggunaan jurnal refleksi mampu } \\
\text { mendokumentasikan pengalaman - pengalaman, } \\
\text { ide - ide, pemikiran - pemikiran, dan kesimpulan } \\
\text { dari study plan yang dirancang mahasiswa." }\end{array}$ & \\
\hline 2. & $\begin{array}{l}\text { Monitoring aktifitas } \\
\text { SDL }\end{array}$ & $\begin{array}{l}\text { "Dokumentasi/catatan belajar dari mahasiswa } \\
\text { dapat digunakan dosen sebagai patokan evaluasi } \\
\text { dari efektifitas self-directed learning." }\end{array}$ & \\
\hline 3. & $\begin{array}{l}\text { Memahami materi } \\
\text { dan proses belajar }\end{array}$ & $\begin{array}{l}\text { "Self-study plan membantu mahasiswa untuk } \\
\text { memahami materi dan proses pembelajaran." }\end{array}$ & \\
\hline 4. & $\begin{array}{l}\text { Membantu } \\
\text { pengaturan proses } \\
\text { belajar }\end{array}$ & $\begin{array}{l}\text { "Study plan dapat mengorganisasikan/mengatur } \\
\text { pemikiran - pemikiran mahasiswa." }\end{array}$ & $\begin{array}{l}\text { "ILP membantu menyelaraskan } \\
\text { learning goals dengan kebutuhan } \\
\text { belajar, dan membantu } \\
\text { mendeteksi kemajuan dalam } \\
\text { pencapaian learning goals" }\end{array}$ \\
\hline 5. & $\begin{array}{l}\text { Menumbuhkan } \\
\text { motivasi }\end{array}$ & $\begin{array}{l}\text { "Memotivasi diri untuk melakukan evaluasi } \\
\text { belajar dan mencari strategi belajar yang sesuai." }\end{array}$ & \\
\hline 6. & $\begin{array}{l}\text { Mempromosikan } \\
\text { lifelong learning }\end{array}$ & & $\begin{array}{l}\text { "ILP mempromosikan belajar } \\
\text { seumur hidup (lifelong learning) } \\
(42 \%) . "\end{array}$ \\
\hline
\end{tabular}

Manfaat pertama penggunaan study planner adalah untuk melakukan refleksi diri. Refleksi diri merupakan salah satu bentuk proses evaluasi diri dengan cara bercermin pada diri sendiri, untuk melihat dan mengingat kembali kegiatan atau perilaku yang sudah dilakukan, untuk mengetahui
$\mathrm{Li}$, et. $\mathrm{Al}, 2010^{8}$ apakah kegiatan atau perilaku tersebut dapat memberikan keuntungan dan memberikan hal yang baik pada diri seseorang atau tidak. Kegiatan refleksi diri ini merupakan bagian penting yang harus dilakukan pada proses self-directed learning. Dengan 
melakukan refleksi diri pada proses self-directed learning pembelajar dapat mengetahui hambatan dan kendala ketika melakukan proses belajar, memilih strategi dan sumber belajar yang terbaik, untuk memahami ilmu yang akan dipelajari. Refleksi diri ini bisa dituliskan mahasiswa pada study planner atau sejenisnya sebagai bahan pembuktian dari mahasiswa atau sebuah dokumentasi dari proses belajar mandiri yang telah berlangsung. ${ }^{4,9}$

Selain itu, penulisan jurnal refleksi pada study planner dapat membantu mahasiswa mengetahui strategi - strategi belajar yang kurang sesuai ataupun bahan belajar yang kurang cocok digunakan dalam mencapai tujuan pembelajaran, sehingga mahasiswa tidak membuang waktu belajar dengan melakukan kesalahan yang sama. Melakukan refleksi diri dapat menumbuhkan rasa kepemilikan terhadap proses belajar dan dapat menumbuhkan motivasi belajar dalam diri mahasiswa untuk menjadi lebih baik. ${ }^{3,5}$

Manfaat kedua dari penggunaan study planner adalah untuk monitoring aktifitas self-directed learning. Monitoring ${ }^{9}$ atau self-monitoring ${ }^{10}$ mengarah kepada proses kognitif dan metakognitif. Mahasiswa melakukan pemantauan pengulangan terhadap strategi belajar yang digunakan, yang disertai dengan kesadaran dan kemampuan untuk berfikir tentang pemikiran mereka (rencana dan memodifikasi proses berfikir sesuai dengan tugas/tujuan pembelajaran). Pengembangan keterampilan dalam memonitor belajar mandiri dengan efektif merupakan kunci utama dari proses self-directed learning yang baik, dan dapat memastikan pengulangan keseluruhan proses belajar. ${ }^{9}$ Dalam proses memonitor belajar mandiri diperlukan alat bantu seperti catatan belajar atau jurnal refleksi, dan lain sebagainya, yang digunakan sebagai bahan pembuktian terlaksananya proses belajar mandiri, dan untuk melihat sampai dimana dan bagaimana proses belajar berlangsung. ${ }^{4}$

Proses memonitor belajar atau monitoring, selain dapat menjadi bahan evaluasi belajar mandiri mahasiswa, mahasiswa juga dapat mengetahui kemajuan atau kemunduran dalam belajar, sehingga mahasiswa dapat langsung mengganti strategi belajar atau sumber belajar ataupun waktu belajar apabila diperlukan, sehingga mahasiswa dapat melakukan proses belajar mandiri dengan lebih efektif dan efisien. ${ }^{4,9,10}$
Manfaat ketiga dari penggunaan study planner adalah membantu memahami materi dan proses pembelajaran. Study plan atau sejenisnya dapat memberikan kekuatan otonomi pada proses belajar mandiri mahasiswa sehingga mahasiswa dapat mengetahui dan memahami hal yang harus dipelajari dan cara mencapai tujuan pembelajaran ingin dicapai mahasiswa. ${ }^{4}$ Otonomi belajar yang disebutkan oleh Challis ${ }^{4}$ memberikan ruang gerak yang luas bagi mahasiswa untuk melakukan proses pembelajaran. Mahasiswa bisa mengeksplorasi proses belajar mereka dalam mencapai tujuan pembelajaran. Eksplorasi belajar ini bisa dilakukan mahasiswa dengan memilih strategi, sumber, waktu, dan tempat belajar yang dirasa sesuai untuk mereka. Penggunaan study planner disini adalah sebagai catatan bagi mahasiswa apabila strategi, sumber, waktu ataupun tempat mereka melakukan proses pembelajaran dirasa tidak sesuai dan hasil belajar mereka tidak seperti yang mereka harapkan. Berdasarkan catatan dalam study planner ini, mahasiswa bisa mengganti strategi, sumber, waktu atau tempat belajar yang sesuai bagi mereka.

Manfaatkeempat dari penggunaan study planneradalah untuk membantu mengatur proses pembelajaran. Dalam proses belajar mandiri, mahasiswa yang menentukan sendiri apa, bagaimana, kapan, dimana proses belajar mandiri berlangsung. Karena itu, mahasiswa sebaiknya diajak untuk mengembangkan sebuah rencana belajar yang akan membantu proses belajar mandiri.

Seperti yang telah disebutkan bahwa pengembangan study planner atau sejenisnya dapat memberikan kekuatan otonomi pada proses belajar. ${ }^{4}$ Dengan kekuatan otonomi ini, mahasiswa secara mandiri dapat mengatur proses belajar mandiri yang akan mereka kerjakan. Perencanaan belajar yang mereka tuliskan dalam study planner dapat digunakan sebagai alat bantu untuk memetakan dan mengingatkan hal-hal yang harus mereka kerjakan dalam belajar mandiri, sebagai alat bantu pengingat (reminder) waktu belajar mandiri, dan sebagai alat bantu check-list setelah mereka selesai melakukan belajar mandiri. Dengan bantuan study planner, mahasiswa bisa menggunakan kekuatan otonomi proses belajar mereka semaksimal mungkin, agar dapat mencapai tujuan pembelajaran yang mereka inginkan. 
Manfaat kelima dari penggunaan study planner adalah untuk menumbuhkan motivasi. Sebuah proses belajar mandiri memberikan rasa tanggung jawab pada mahasiswa atas proses belajar yang sedang berlangsung dan dapat menumbuhkan motivasi dalam diri mahasiswa tersebut. Penggunaan sebuah study planner dapat mendorong dan memotivasi untuk melakukan pendalaman dalam belajar dan dapat membantu mahasiswa tugas - tugas belajar yang bersifat self-directed. ${ }^{3,4}$

Menumbuhkan motivasi belajar disini bisa terjadi ketika mahasiswa melihat kembali catatan yang sudah mereka tuliskan dalam study planner. Berdasarkan catatan tersebut mahasiswa dapat mengetahui sejauh mana mereka memahami materi yang telah mereka pelajari. Dengan mengetahui kemajuan belajar serta mengetahui tingkat pengetahuan diri, dapat memberikan rasa percaya diri dan dapat menumbuhkan motivasi serta menumbuhkan keinginan bagi mahasiswa untuk melakukan pendalaman belajar, Selain itu, catatan dalam study planner ini dapat digunakan mahasiswa sebagai bahan refleksi belajar mahasiswa, dalam rangka pengembangan diri untuk menjadi lebih baik di masa datang. Refleksi diri ini dapat memberikan rasa kepemilikan atas keseluruhan proses belajar yang telah dan akan berlangsung. Selain itu, refleksi diri ini dapat membantu mahasiswa untuk melatih kesadaran diri akan pentingnya ilmu yang mereka peroleh dalam proses belajar mandiri dan kegunaan hasil belajar mandiri tersebut kepada diri mereka sendiri. ${ }^{4,9}$

Manfaat terakhir yang ditemukan dari penggunaan study planner adalah untuk mempromosikan lifelong learning. Study planner atau sejenisnya dapat menjadi sebuah siklus dari proses pengembangan diri yang diperlukan mahasiswa untuk masa datang. ${ }^{4}$ Ada beberapa langkah yang harus diikuti dalam melakukan self-directed learning, yaitu: planning, implementing, monitoring, dan evaluating/reflection. ${ }^{9}$
Langkah - langkah ini merupakan sebuah siklus kebiasaan belajar yang senantiasa harus dilakukan apabila seseorang ingin melakukan self-directed learning. Ada juga beberapa langkah yang harus dilakukan apabila mahasiswa ingin menyusun sebuah study planner yaitu (1) Melakukan refleksi belajar, untuk mengetahui kekosongan dalam pengetahuan (knowledge gap); (2) Membuat sebuah perencanaan belajar, yang kemudian dituliskan dalam study planner; (3) Membuat sebuah catatan belajar mandiri yang digunakan sebagai barang bukti terlaksananya proses belajar dan sebagai sebuah check list proses belajar yang sudah mereka laksanakan; (4) Melakukan evaluasi belajar, baik dalam bentuk selfassessment atau melakukan sebuah refleksi belajar, dan mencatat hasil evaluasi belajar ini pada study planner, evaluasi disini adalah untuk mengetahui sejauh mana mahasiswa memahami materi belajar yang baru mereka pelajari; (5) Membuat perencanaan belajar baru berdasarkan hasil evaluasi belajar dan menuliskannya dalam study planner. ${ }^{4}$

Bisa disimpulkan disini bahwa, pada saat mahasiswa menyusun sebuah study planner, secara tidak langsung mahasiswa melakukan proses self-directed learning. Langkah dari self-directed learning dan langkah - langkah pengembangan penyusunan study planner ini merupakan sebuah siklus yang terus berkelanjutan dalam sebuah proses belajar mandiri. Keterampilan ini dapat membantu mahasiswa dalam melatih sebuah kebiasaan belajar dan pengulangan proses belajar ketika mahasiswa selesai mengikuti pendidikan. Berdasarkan langkah - langkah tersebut bisa kita simpulkan bahwa, penggunaan study planner dapat membantu mempromosikan lifelong learning.

Faktor-faktor yang mempengaruhi study planner dan self-directed learning, sangat luas dan berasal dari berbagai pihak yang keseluruhannya berperan secara kuat. Faktor-faktor tersebut dapat dilihat pada tabel 3. 
Tabel 3. Faktor-faktor yang mempengaruhi study planner atau sejenisnya dan SDL

\begin{tabular}{|c|c|c|c|}
\hline No. & \multicolumn{3}{|c|}{ Faktor - faktor yang mempengaruhi Study Planner dan Self-Directed Learning } \\
\hline I. & Dosen & Du, 2012 & Li, et. $\mathrm{Al}, 2010^{8}$ \\
\hline \multirow[t]{2}{*}{ A. } & \multirow[t]{2}{*}{$\begin{array}{l}\text { Peran dan } \\
\text { tanggung jawab }\end{array}$} & $\begin{array}{l}\text { "Bagi dosen, mengubah peran sebagai pemimpin kelas menjadi } \\
\text { seorang fasilitator pada SDL sangatlah menyulitkan dan tidak } \\
\text { menyenangkan." }\end{array}$ & \\
\hline & & $\begin{array}{l}\text { "Dosen - dosen perlu memahami dengan baik peran dan } \\
\text { tanggung jawab mereka dalam program pendidikan berbasis } \\
\text { SDL }\end{array}$ & \\
\hline & \multirow[t]{2}{*}{$\begin{array}{l}\text { Memonitor } \\
\text { pelaksanaan dan } \\
\text { perkembangan } \\
\text { aktifitas SDL }\end{array}$} & $\begin{array}{l}\text { "Dosen haruslah membuat pertemuan dengan mahasiswa } \\
\text { menjadi sebuah rutinitas, untuk memonitor perkembangan } \\
\text { belajar mahasiswa." }\end{array}$ & $\begin{array}{l}\text { "Residen memiliki } \\
\text { bimbingan/mentoring } \\
\text { yang efektif dari } \\
\text { Dosen untuk } \\
\text { membantu mereka } \\
\text { menindaklanjuti } \\
\text { rencan belajar } \\
\text { mereka." }\end{array}$ \\
\hline & & $\begin{array}{l}\text { "Dosen haruslah memeriksa dengan teliti dan seksama study } \\
\text { plan yang telah disusun oleh mahasiswa yang kurang memiliki } \\
\text { keterampilan dalam self-directed learning, yaitu, mahasiswa } \\
\text { yang kurang mampu mengenali dan mendiagnosa kelebihan dan } \\
\text { kekurangannya sendiri." }\end{array}$ & \\
\hline & \multirow[t]{5}{*}{$\begin{array}{l}\text { Memberikan } \\
\text { feedback }\end{array}$} & $\begin{array}{l}\text { "Dosen haruslah memberikan motivasi dan bekerjasama dengan } \\
\text { mahasiswa untuk membuat perubahan - perubahan yang } \\
\text { diperlukan agar proses self-directed learning terlaksana dengan } \\
\text { baik." }\end{array}$ & \\
\hline & & $\begin{array}{l}\text { "Dosen berdiskusi dengan mahasiswa - mahasiswa yang } \\
\text { tidak mampu membuat dokumentasi belajar, untuk mencari } \\
\text { akar permasalahan dan alasan - alasan mengapa mereka } \\
\text { tidak mampu membua catatan tersebut dan membantu } \\
\text { menyelesaikan permasalahan tersebut." }\end{array}$ & \\
\hline & & $\begin{array}{l}\text { "Dosen harus menjelaskan poin - poin yang dirasa perlu } \\
\text { untuk diberikan feedback, dimana feedback ini diberikan per- } \\
\text { individu." }\end{array}$ & \\
\hline & & $\begin{array}{l}\text { "Pada saat pemberian feedback, dosen harus memperhatikan } \\
\text { faktor - faktor penting pada mahasiswa: } \\
\text { a. Gaya belajar mahasiswa } \\
\text { b. Kelebihan dan kekurangan mahasiswa pada tingkat } \\
\text { pengetahuan. } \\
\text { c. Critical thinking skills. } \\
\text { d. Self-monitoring skills. } \\
\text { e. Emotional maturity level." }\end{array}$ & \\
\hline & & $\begin{array}{l}\text { "Pada mahasiswa yang dijumpai memiliki level keterampilan } \\
\text { self-directed learning yang lemah, dosen memberikan arahan } \\
\text { yang lebih terstruktur, sistematik dan detail, pada saat } \\
\text { pemberian feedback." }\end{array}$ & \\
\hline
\end{tabular}




\begin{tabular}{ll}
\hline $\begin{array}{l}\text { Memonitor } \\
\text { dokumen belajar }\end{array}$ & $\begin{array}{l}\text { "Secara periode, tim dosen meminta mahasiswa untuk membuat } \\
\text { sebuah dokumentasi (berupa catatan) hasil belajar, dan } \\
\text { dokumentasi ini akan di-review oleh dosen." }\end{array}$ \\
\hline Melakukan & "Mahasiswa berpendapat bahwa dosen haruslah lebih \\
follow-up & memperhatikan dalam memeriksa study plan dan melakukan \\
& follow-up." \\
\hline
\end{tabular}

II. Mahasiswa

Du, 2012

Li, et. Al, 2010

A. Pengembangan study planner

Proses

pengembangan

Planning,

Implementing,

Monitoring, dan

Evaluasi (self-

reflection, self-

assessment) pada

study planner atau

sejenisnya.

\begin{abstract}
"Mahasiswa mendemonstrasikan berbagai tingkat kompetensi dalam hal mempersempit learning objektif yang dapat membantu mahasiswa untuk menentukan learning objektif yang tepat"
\end{abstract}

"Meskipun residen memiliki kepercayaan diri akan kemampuan mereka untuk mengidentifikasi kekuatan mereka atau area keterampilan yang perlu ditingkatkan, residen merasa kurang percaya diri akan kemampuan mereka untuk menyusun learning goals yang dapat membantu meningkatkan performa mereka, mengembangkan rencana belajar yang efektif untuk mencapai learning goals, dan mengerjakan seluruh rencana belajar yang telah mereka buat."

"Sejumlah kecil residen melaporkan bahwa mereka memliki waktu yang cukup untuk mengembangkan ILP yang efektif."

"Banyak residen melaporkan kesulitan mengingat untuk mengerjakan tujuan belajar mereka dan beberapa residen mendeteksi kemajuan belajar mereka sendiri."

"Residen menggunakan sebuah sistem untuk mendeteksi kemajuan mereka ke arah pencapaian learning goals."

"Residen kurang percaya diri akan kemampuan mereka untuk membuat learning goals yang spesifik untuk mengatasi kekurangan yang sebelumnya mereka identifikasi sendiri, dan mengembangkan serta mengikuti rencana belajar yang sesuai dengan learning goals tersebut."

"Kami menemukan 3 karakteristik residen yang besar kaitannya dengan tingkat keberhasilan pencapaian learning goals SDL, dengan menggunakan ILP :

1. Penggunaan metode - metode yang mampu mendeteksi kemajuan menuju pencapaian learning goals. 2. Kecenderungan residen terhadap lifelong learning.

3. Perilaku dan kepercayaan diri akan kemampuan melakukan SDL." 


\begin{tabular}{|c|c|c|c|}
\hline \multirow[t]{2}{*}{ B. } & \multirow[t]{2}{*}{$\begin{array}{c}\text { Karakteristik } \\
\text { mahasiswa }\end{array}$} & & $\begin{array}{l}\text { "Faktor dari tingkat mahasiswa } \\
\text { lebih erat kaitannya dengan } \\
\text { kemajuan menuju pencapaian tujuan } \\
\text { pembelajaran SDL dibandingkan } \\
\text { dengan faktor dari tingkat program } \\
\text { pendidikan". }\end{array}$ \\
\hline & & & $\begin{array}{l}\text { "Level karakteristik mahasiswa memiliki } \\
\text { hubungan yang sangat besar terhadap } \\
\text { kemajuan belajar mahasiswa menuju } \\
\text { pencapaian learning goals." }\end{array}$ \\
\hline & \multirow[t]{3}{*}{$\begin{array}{l}\text { Sifat \& } \\
\text { kepribadian }\end{array}$} & $\begin{array}{l}\text { "Mahasiswa - mahasiswa yang memiliki sifat } \\
\text { "introvert", dimana, gaya belajar mereka } \\
\text { bersifat analitik dan sequential memperlihatkan } \\
\text { penerimaan SDL dengan lebih antusias bila } \\
\text { dibandingkan dengan mahasiswa yang bersifat } \\
\text { "extrovert", dimana gaya belajar mereka lebih } \\
\text { sintetik dan random." }\end{array}$ & $\begin{array}{l}\text { "Meskipun residen memiliki } \\
\text { kepercayaan diri akan kemampuan } \\
\text { mereka untuk mengidentifikasi } \\
\text { kekuatan mereka atau area } \\
\text { keterampilan yang perlu ditingkatkan, } \\
\text { residen merasa kurang percaya diri akan } \\
\text { kemampuan mereka untuk menyusun } \\
\text { learning goals yang dapat membantu } \\
\text { meningkatkan performa mereka, } \\
\text { mengembangkan rencana belajar yang } \\
\text { efektif untuk mencapai learning goals, } \\
\text { dan mengerjakan seluruh rencana } \\
\text { belajar yang telah mereka buat." }\end{array}$ \\
\hline & & $\begin{array}{l}\text { "Beberapa gaya belajar dan kepribadian yang } \\
\text { bersifat intrinsik kurang dapat menerima } \\
\text { intervensi dari luar seperti arahan atau } \\
\text { feedback dari dosen." }\end{array}$ & $\begin{array}{l}\text { "Residen berjenis kelamin wanita dan } \\
\text { residen yang belum memutuskan arah } \\
\text { pendidikan ataupu jenis karir dimasa } \\
\text { datang berhubungan atau mempunyai } \\
\text { sedikit kemajuan pada proses } \\
\text { pencapaian learning goals." }\end{array}$ \\
\hline & & & $\begin{array}{l}\text { "Keyakinan akan keberhasilan diri } \\
\text { dapat memberikan pengaruh yang } \\
\text { positif terhadap penampilan dimasa } \\
\text { datang." }\end{array}$ \\
\hline & \multirow[t]{2}{*}{ Gaya belajar } & $\begin{array}{l}\text { "Mahasiswa - mahasiswa yang memiliki } \\
\text { sifat "introvert", gaya belajar mereka bersifat } \\
\text { analitik dan sequential memperlihatkan } \\
\text { penerimaan SDL dengan lebih antusias bila } \\
\text { dibandingkan dengan mahasiswa yang bersifat } \\
\text { "extrovert", dimana gaya belajar mereka lebih } \\
\text { sintetik dan random." }\end{array}$ & $\begin{array}{l}\text { "Kecenderungan lebih besar untuk } \\
\text { terlibat dalam perilaku lifelong learning } \\
\text { berkaitan dengan kesuksesan dalam } \\
\text { pencapaian tujuan pembelajaran, } \\
\text { tingkat pelatihan mandiri, atau gaya } \\
\text { belajar." }\end{array}$ \\
\hline & & $\begin{array}{l}\text { "Beberapa gaya belajar dan kepribadian yang } \\
\text { bersifat intrinsik kurang dapat menerima } \\
\text { intervensi dari luar seperti arahan atau } \\
\text { feedback dari dosen." }\end{array}$ & \\
\hline
\end{tabular}




\begin{tabular}{|c|c|c|c|}
\hline & \multirow[t]{4}{*}{$\begin{array}{l}\text { Tingkat } \\
\text { keterampilan } \\
\text { SDL }\end{array}$} & $\begin{array}{l}\text { "Pada mahasiswa yang terlihat memiliki } \\
\text { level advance dari self-directed learning skills, } \\
\text { sepertinya memiliki kemampuan dalam } \\
\text { fleksibilitas dan kontrol diri." }\end{array}$ & $\begin{array}{l}\text { Resident yang memiliki kepercayaan } \\
\text { iri atas kemampuan self-directed } \\
\text { earning mereka, dilaporkan lebih } \\
\text { nemiliki kesuksesan dalam belajar." }\end{array}$ \\
\hline & & \multicolumn{2}{|l|}{$\begin{array}{l}\text { "Mahasiswa yang memiliki keterampilan SDL } \\
\text { yang terbatas mengakibatkan terbatasnya } \\
\text { tingkat pengetahuan, kompetensi dan } \\
\text { pengalaman dalam critical thinking, self- } \\
\text { assessment, dan refleksi diri" }\end{array}$} \\
\hline & & \multicolumn{2}{|l|}{$\begin{array}{l}\text { "Dijumpai pada beberapa mahasiswa, } \\
\text { mempraktekkan SDL menimbulkan rasa } \\
\text { frustasi, yang menyebabkan mereka bertanya- } \\
\text { tanya dan sampai meragukan kegunaan SDL } \\
\text { itu sendiri." }\end{array}$} \\
\hline & & \multicolumn{2}{|l|}{$\begin{array}{l}\text { "Mahasiswa yang memiliki advance skills dari } \\
\text { SDL memperlihatkan ketidaksukaan dengan } \\
\text { keterbatasan dari kurikulum tradisional." }\end{array}$} \\
\hline \multirow{2}{*}{\multicolumn{2}{|c|}{$\begin{array}{l}\text { Preferensi } \\
\text { kurikulum }\end{array}$}} & \multicolumn{2}{|l|}{$\begin{array}{l}\text { "Mahasiswa yang lebih menyukai pendidikan yang } \\
\text { bersifat teacher-centered akan menganggap, membuat } \\
\text { study plan untuk belajar mandiri merupakan kegiatan } \\
\text { yang tidak penting atau berguna." }\end{array}$} \\
\hline & & \multicolumn{2}{|l|}{$\begin{array}{l}\text { "Pada penelitian ini terlihat } 2 \text { orang mahasiswa } \\
\text { membuat study plan yang singkat dan bersifat umum, } \\
\text { yang mengindikasikan kurangnya ketertarikan pada } \\
\text { SDL" }\end{array}$} \\
\hline III. & Kurikulum & Du, 2012 & Li, et. Al, 2010 \\
\hline \multirow[t]{4}{*}{1.} & $\begin{array}{l}\text { Bentuk } \\
\text { kurikulum }\end{array}$ & $\begin{array}{l}\text { "Kurikulum tradisional yang bersifat teacher-centered, } \\
\text { dimana aktifitas belajar-mengajar sangatlah dipengaruhi } \\
\text { oleh dosen, bukan mahasiswa (self-directed)." }\end{array}$ & $\begin{array}{l}\text { "Sebagian besar resident menunjukkan } \\
\text { bahwa mereka memiliki kesempatan untuk } \\
\text { melatih area - area keterampilan yang } \\
\text { dirasa perlu untuk ditingkatkan. }\end{array}$ \\
\hline & & $\begin{array}{l}\text { "Kedua filosifi pendidikan (teacher-centered dan SDL) ini } \\
\text { dapat saling mendukung satu sama lain atau dapat juga } \\
\text { membuat kebingungan dan menimbulkan abiguitas baik } \\
\text { pada mahasiswa maupun dosen." }\end{array}$ & $\begin{array}{l}\text { "membuat sebuah sistem yang dapat } \\
\text { mempermudah resident untuk mendeteksi } \\
\text { kemajuan menuju pencapaian learning } \\
\text { goals sangat efektif dan dapat memberikan } \\
\text { keuntungan pada investasi tersebut." }\end{array}$ \\
\hline & & $\begin{array}{l}\text { "Bagi dosen yang terbiasa dengan pendidikan yang } \\
\text { bersifat teacher-centered, memfasilitasi SDL merupakan } \\
\text { area yang tidak dikenali/familiar, yang dapat } \\
\text { menyebabkan ketidakpastian pada kemampuan dosen } \\
\text { untuk memfasilitasi SDL dengan baik." }\end{array}$ & \\
\hline & & $\begin{array}{l}\text { "Program pendidikan bahasa, secara struktural } \\
\text { memperlihatkan bagian - bagian yang bertentangan } \\
\text { dengan prinsip SDL." }\end{array}$ & \\
\hline
\end{tabular}




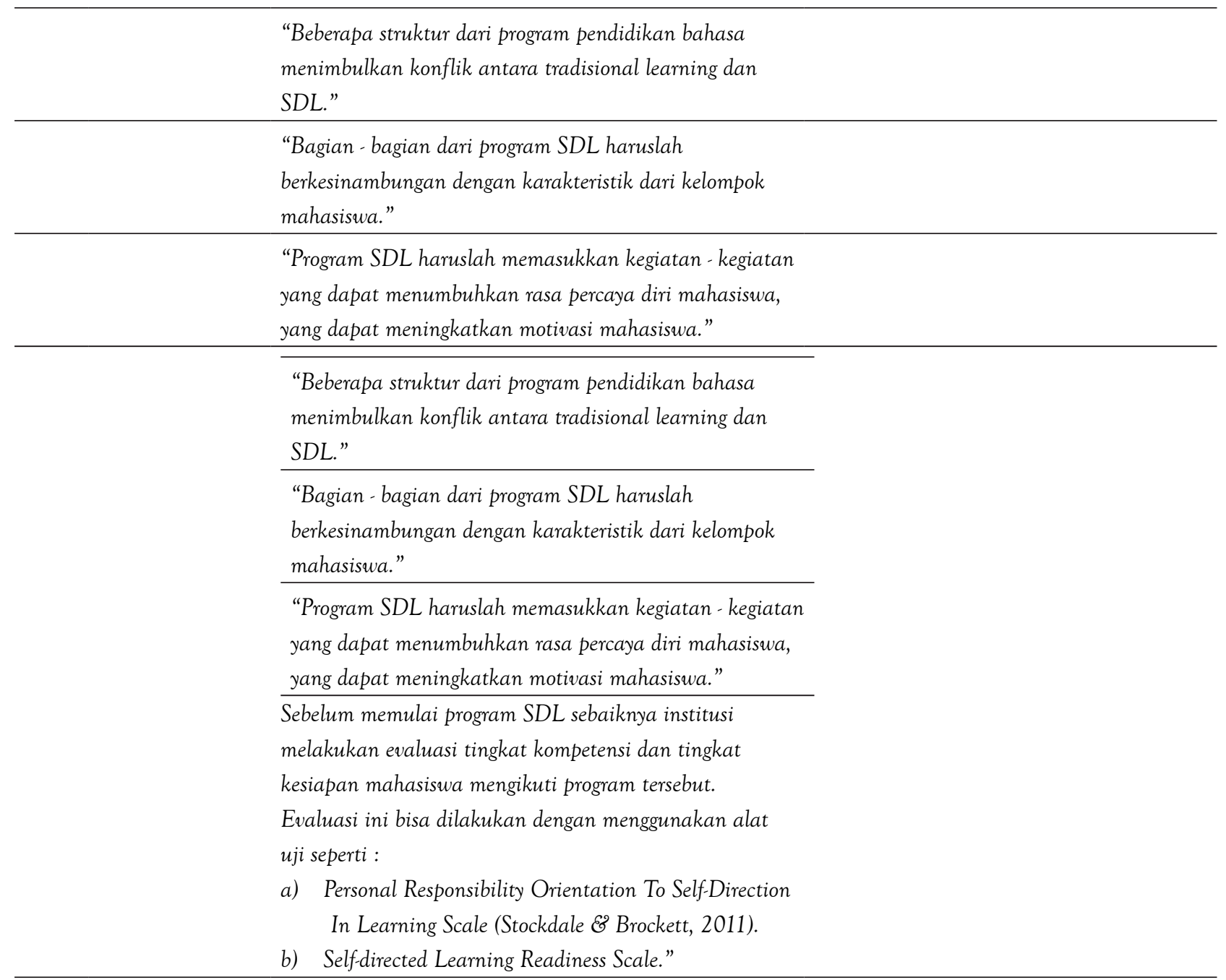

"Beberapa perubahan struktural mungkin diperlukan untuk mengakomodasikan kegiatan SDL, seperti

a. Curriculum planning

b. Scheduling.

c. Ketersediaan sumber belajar."

2. Fleksibilitas "Mahasiswa berharap agar ada perubahan yang fleksibel pada kurikulum yang bersifat SDL."

"Bagi kelompok mahasiswa yang memiliki keterampilan SDL yang tinggi, kurikulum pendidikan haruslah lebih bersifat fleksible dan memberikan lebih banyak waktu dalam belajar mandiri"

"Bagi kelompok mahasiswa yang memiliki keterampilan SDL yang terbatas, maka program SDL haruslah dibuat lebih terstruktur dan bersifat teacher-centered." 


3. waktu $\quad$ Waktu dan standard kurikulum yang harus diberikan
pada mahasiswa tidak mampu memenuhi kebutuhan
belajar mahasiswa yang memiliki keterampilan SDL
yang tinggi, seperti : Meluangkan waktu khusus untuk
belajar mandiri pada kegiatan belajar-mengajar yang
reguler."
"Pelaksanaan program pelatihan SDL yang berjangka
pendek, dengan intensitas yang tinggi dan dilakukan
dalam waktu yang singkat dapat menyebabkan prinsip -
prinsip SDL tidak dapat dilaksanakan."
"Pada penelitian ini, penambahan kelas khusus untuk
pelatihan program SDL tidak dapat terlaksana akibat
waktu pelakasanaan pelatihan untuk program SDL ini
sangat cepat, dan materi yang harus diberikan pada
kurikulum tersebut sangat banyak, sehingga mahasiswa
merasa motivasi mereka berkurang akibat kurangnya
perhatian dan feedback dari dosen"

Faktor pertama yang mempengaruhi study planner dan self-directed learning adalah dosen. Adapun dosen memiliki peran-peran sebagai berikut:

a. Peran dan tanggung jawab:

i. Memonitor pelaksanaan dan perkembangan aktifitas self-directed learning - Salah satu peran dosen pada proses self-directed learning adalah sebagai pendamping atau fasilitator dalam melakukan belajar mandiri yang membantu mahasiswa dalam proses monitoring kegiatan dan aktifitas belajar mandiri. Peran ini sangat penting dalam pembentukan otonomi belajar pada mahasiswa. ${ }^{4,9}$ Peran dosen berubah dari pemberi ilmu pengetahuan atau pemimpin dalam kelas menjadi seorang manajer dari sebuah proses belajar. ${ }^{11}$

ii. Memberikan feedback - Pemberian feedback pada mahasiswa merupakan tanda atau penggambaran dari komitmen dosen kepada mahasiswa dalam hal membantu mahasiswa mencapai tujuan pembelajaran. ${ }^{12}$ Pemberian feedback pada self-directed learning bertujuan untuk membantu mahasiswa dalam proses mengarahkan mahasiswa untuk membuat sebuah tujuan belajar yang dibutuhkan mahasiswa dalam mengatakasi "gap" atau kebutuhan belajar. iii. Memonitor dokumen belajar - Dosen berperan sebagai partner belajar yang bertugas untuk memonitor atau melakukan review terhadap dokumen pembelajaran. ${ }^{4}$ Dokumen belajar ini diperiksa oleh Dosen untuk mengetahui sejauh mana kemajuan proses belajar self-directed learning. Bantuan dalam memonitor belajar ini penting dilakukan, karena, mahasiswa terkadang belum mengetahui dan belum memiliki keterampilan dalam melakukan monitor belajar mereka sendiri. karena itu, diperlukan orang kedua yang mampu membantu mahasiswa dalam melatih dan mengarahkan mahasiswa dalam melakukan monitor belajar. ${ }^{4}$ Disini Dosen dapat melihat secara objektif, proses belajar mandiri yang sudah dilakukan mahasiswa, dengan melihat study planner yang telah disusun oleh mahasiswa.

iv. Melakukan follow-up - Melakukan follow-up pada self-directed learning dapat membantu mahasiswa dalam memastikan proses belajar yang sudah direncanakan dalam study planner, terlaksana dengan baik, sesuai dengan yang direncanakan. Hal ini merupakan peran Dosen sebagai manager proses belajar, ${ }^{11}$ yang dapat membantu 
mahasiswa dalam hal memastikan proses belajar yang sedang berlangsung sesuai dengan yang direncanakan dalan study planner atau sejenisnya.

b. Tingkat pengetahuan dan keterampilan dalam memfasilitasi SDL

Dalam memfasilitasi pengembangan study planner dan menjadi fasilitator dalam proses selfdirected learning diperlukan keterampilan dalam hal 'membantu' mahasiswa dalam memecahkan permasalahan - permasalahan yang timbul pada saat proses belajar berlangsung. ${ }^{4}$ Maka dari itu dosen perlu mengembangkan keterampilan mereka untuk menjadi fasilitator yang efektif pada proses self-directed learning. Mengembangkan keterampilan Dosen dalam menjadi fasilitator yang efektif dapat dilakukan dengan cara institusi melakukan pelatihan mengenai proses self-directed learning dan pelatihan dalam pemberian feedback, ataupun membaca jurnal jurnal yang berkaitan dengan proses self-directed learning dan bagaimana memberikan feedback yang baik kepada mahasiswa. ${ }^{4}$

Faktor kedua yang mempengaruhi study planner dan self-directed learning adalah mahasiswa. Adapun mahasiswa tersebut sendiri memiliki peran-peran sebagai berikut:

a. Pengembangan study planner

Proses pengembangan Planning, Implementing, Monitoring, dan Evaluasi (self-reflection, selfassessment) pada study planner atau sejenisnya.

Seperti yang telah disebutkan sebelumnya, terdapat empat fase penting yang perlu dilakukan mahasiswa dalam melakukan self-directed learning yaitu $^{10}$ : (1) Planning, atau perencanaan belajar, yang meliputi penentuan tujuan pembelajaran yang dapat dicapai, membuat kerangka rencana belajar, menentukan sumber belajar yang sesuai dan melakukan penjadwalan belajar; (2) Implementing, atau menjalankan keseluruhan proses rencana belajar yang telah disusun; (3) Monitoring, yaitu, melakukan pengawasan belajar mandiri; dan (4) Evaluasi, untuk menilai keseluruhan proses belajar yang telah berlangsung. ${ }^{10}$ Keseluruhan siklus ini bisa dimuat di dalam study planner atau yang sejenisnya, sebagai pengingat kepada mahasiswa, untuk mengerjakan belajar mandiri mereka. ${ }^{4}$ Selain itu, mahasiswa perlu membuat kerangka dan rencana belajar yang feasible agar proses selfdirected learning dapat terlaksana dengan baik.

b. Karakteristik mahasiswa

Dalam studi literatur ditemukan bahwa "Level karakteristik mahasiswa memiliki hubungan yang sangat besar terhadap kemajuan belajar mahasiswa menuju pencapaian learning goals". ${ }^{8}$ Karakter mahasiswa ini bisa dilihat pada pembagian berikut, yaitu:

i. Sifat dan kepribadian - Berdasarkan temuan Du (2012), dinyatakan bahwa "Mahasiswa - mahasiswa yang memiliki sifat "introvert", dimana, gaya belajar mereka bersifat analitik dan sequential memperlihatkan penerimaan SDL dengan lebih antusias bila dibandingkan dengan mahasiswa yang bersifat "extrovert", dimana gaya belajar mereka lebih sintetik dan random." 7

ii. Gaya belajar - Dalam studi literatur, ditemukan bahwa ada beberapa gaya belajar yang kurang mampu menerima intervensi dari luar. Intervensi ini bisa berupa pemberian feedback dari Dosen. ${ }^{7}$ Selain itu, mahasiswa yang menyukai metode pengajaran tradisional, seperti mengikuti kuliah ataupun seminar, dimana dosen ahli yang memberikan pengetahuan kepada mahasiswa, mungkin tidak menyukai kegiatan dalam mengembangkan rencana belajarnya sendiri. ${ }^{4}$

iii. Tingkat keterampilan SDL - Bagi mahasiswa yang belum pernah mengikuti pendidikan yang bersifat independent learning, melakukan self-directed learning tentunya sangat menyulitkan. Dalam independent learning, mahasiswa diajak untuk memutuskan sendiri proses belajar yang akan mereka lakukan. ${ }^{1,2}$ Oleh sebab itu, mahasiswa ini memerlukan seorang pendamping belajar yang mampu membantu mengarahkan mahasiswa, sekaligus melatih keterampilan mahasiswa dalam melakukan belajar mandiri. Keterampilan ini diperlukan 
mahasiswa dalam dunia kerja, dimana, dokter diminta untuk selalu melakukan update ilmu pengetahuan mereka.

iv. Preferensi kurikulum - Seperti yang disebutkan sebelumnya, mahasiswa yang lebih menyukai metode pengajaran tradisional kurang menyukai aktifitas belajar yang menuntut mereka untuk mengembangkan sebuah rencana belajar mandiri, menjelaskan proses belajar mandiri mereka berlangsung, ataupun menilai dan menjelaskan kekurangan belajar yang mereka miliki. ${ }^{4}$

Berdasarkan temuan-temuan diatas, dosen dan institusi perlu membantu mengarahkan mahasiswa dalam proses pengembangan karaktek belajar yang dapat membantu mahasiswa mengembangkan keterampilan dalam melakukan self-directed learning. ${ }^{4}$ Yang harus diingat oleh institusi disini adalah tujuan dari pengembangan study planner adalah untuk mengajak mahasiswa untuk membentuk otonomi belajar dan melatih kebiasaan melakukan lifelong learning, bukan membuat sebuah beban belajar baru bagi mahasiswa. ${ }^{4}$

Faktor ketiga yang mempengaruhi study planner dan self-directed learning adalah kurikulum. Adapun kurikulum memiliki peran-peran sebagai berikut:

Bentuk kurikulum

a. Ada beberapa prinsip dalam melaksanakan program pendidikan self-directed learning, yaitu: (1) Program pendidikan harus bersifat sama (kongruen) dengan kehidupan belajar, cara alami untuk belajar dan metode belajar yang unik, yang digunakan dari oleh mahasiswa, yang dirasa paling baik untuk belajar; (2) Program pendidikan harus disesuaikan dengan tingkat pematangan, transformasi dan transisi yang dialami mahasiswa; (3) Program pendidikan harus mempertingkan seluruh aspek kehidupan, Gibbons (2002) menyebutkan bahwa pendidikan yang bersifat akademis merupakan hal penting dan termasuk pada program self-directed learning, tetapi juga merupakan domain pribadi (personal), sosial, dan bagian dari pengalaman manusia ${ }^{13}$; (4) Proses belajar dalam program self-directed learning mempertimbangkan berbagai kapasitas manusia, termasuk indera, emosi, tindakan, serta kecerdasan manusia tersebut.; dan yang terakhir (5) Kegiatan self-directed learning harus dikerjakan pada situasi yang dapat membantu pengembangan belajar mahasiswa. ${ }^{13}$

b. Fleksibilitas

Dalam mengembangkan program yang menggunakan prinsip self-directed learning, kurikulum yang ada haruslah bersifat fleksibel dan disesuaikan dengan tingkat kemampuan mahasiswa yang akan menggunakan kurikulum tersebut. Sehingga kurikulum yang ada dapat membantu mengarahkan dan semakin memotivasi mahasiswa untuk melakukan proses self-directed learning.

c. Waktu

Pengembangan kurikulum untuk metode atau filosofi pendidikan apapun akan tidak efektif dan tidak memberikan hasil yang baik apabila dikerjakan dalam waktu yang singkat dan terburu-buru. Karena itu, sebelum menjalankan program baru, institusi sebaiknya merancang program atau kurikulum tersebut dengan jelas dan terperinci, yang kemudian dilanjutkan dengan uji coba kurikulum kepada mahasiswa, yang merupakan "client" pengguna kurikulum tersebut. Pengembangan kurikulum apapun akan memberikan hasil yang baik apabila dikerjakan dengan cermat.

\section{KESIMPULAN}

Dari hasil penelitian di atas, dapat disimpulkan bahwa study planner dapat membantu mahasiswa dalam mengembangkan keterampilan dalam melakukan siklus belajar self-directed learning yang berguna untuk melakukan keterampilan life-long learning. Selain itu, study planner ini juga dapat memberikan motivasi kepada mahasiswa dalam melakukan proses selfdirected learning.

\section{DAFTAR PUSTAKA}

1. Silén C, Uhlin L. Self-Directed Learning - A Learning Issue for Students and Faculty. Teaching in Higher Education, 2008; 13(4): 461-75.

2. Miflin BM, Campbell CB, Price DA. A Conceptual Framework to Guide The Development of Self-Directed, Lifelong Learning 
in Problem-Based Medical Curricula. Medical Education, 2000; 34: 299-306.

3. Harden RM. Independent Learning. In: Dent, J. A. \& Harden, R. M. A Practical Guide for Medical Teachers. England: Elsevier; 2009, pp. 168-73.

4. Challis M. Personal Learning Plan. Medical Teachers, 2000; 22(19): 226-36.

5. Bandaranayake RC. Study Skills. In: Dent, J. A. \& Harden, R. M. A Practical Guide for Medical Teachers. England: Elsevier; 2009, pp. 385 - 390.

6. Johson B, Christensen L. Educational Research Quantitative, Qualitative, and Mixed Approach. $4^{\text {th }}$ ed. United States of America: Sage Publication; 2012, Ch. 2, pp. 48-49; Ch. 8, pp. 202 - 212; Ch. 10, pp. 264 - 273; Ch. 14, pp. 383 - 388; Ch. 19 , pp. $517-525$.

7. Du FN. Using Plans To Develop Self-Directed Learning Skills: Implication From A Pilot Project. College Student Journal, 2012; 46(1): 223. 32.

8. Li ST, Tancredi DJ, Patrick TJ, West DC. Factors Associated with Successful Self-Directed
Learning Using Individualizes Learning Plan During Pediatric Residency. Academic Pediatric, 2010; 10(2): 124-30.

9. Thornton K. Supporting Self-Directed Learning: A Framework for Teachers [Internet]. Language Education in Asia, 2010; 1(1): 158-70. Available from: http://dx.doi.org/10.5746/LEiA/10/ V1/A14/Thornton (Accessed: 10 Mei 2015)

10. Garrison DR. Self-Directed Learning: Toward A Comprehensive Model. Adult Education Quarterly, 1997; 48(1): 18-33.

11. Harden RM, Crosby J. The Good Teacher is More Than a Lecturer - the twelve roles of the teacher. Medical Teacher, 2000; 22(20): 334-47.

12. Krakov SK. Giving Feedback. In: Dent, J. A. \& Harden, R. M. A Practical Guide for Medical Teachers. England: Elsevier; 2009, pp. 357-64.

13. Gibbon M. The Self-Directed Learning Handbook: Challenging Adolescent Student to Excel. United States of America: Jossey - Bass; 2002, pp. 1-13. 